\title{
Patient-Centered Medical Home Among Small Urban Practices Serving Low-Income and Disadvantaged Patients
}

Carolyn A. Berry, $P b D^{1}$

Tod Mijanovich, $P b D^{2}$

Stephanie Albert, $M P A^{1}$

Chloe H. Winther, $B A^{3}$

Margaret M. Paul, MS ${ }^{1}$

Mandy Smith Ryan, $P b D^{3}$

Colleen $\mathrm{McC}$ Cullough, $B A^{3}$

Sarab C. Sbib, MPH

'Department of Population Health,

New York University School of Medicine, New York, New York

${ }^{2}$ Robert F. Wagner Graduate School of Public Service, New York University, New York, New York

${ }^{3}$ Primary Care Information Project, New York City Department of Health and Mental Hygiene, Long Island City, New York

Conflicts of interest: authors report none.

\section{CORRESPONDING AUTHOR}

Carolyn A. Berry, PhD

Department of Population Health

New York University School of Medicine 227 E 30th St, 6th Floor

New York, NY 10016

Carolyn.berry@nyumc.org

\begin{abstract}
PURPOSE Research on the patient-centered medical home (PCMH) model and practice redesign has not focused on the unique challenges and strengths of very small primary care practices serving disadvantaged patient populations. We analyzed the practice characteristics, prior experiences, and dimensions of the PCMH model that exist in such practices participating in the Primary Care Information Project (PCIP) of the New York City Department of Mental Health and Hygiene.
\end{abstract}

METHODS We obtained descriptive data, focusing on $\mathrm{PCMH}$, for 94 primary care practices with 5 or fewer clinicians serving high volumes of Medicaid and minority patient populations in New York City. Data included information extracted from PCIP administrative data and survey data collected specifically for this study.

RESULTS Survey results indicated substantial implementation of key aspects of the $\mathrm{PCMH}$ among small practices serving disadvantaged patient populations, despite considerable potential challenges to achieving PCMH implementation. Practices tended to use few formal mechanisms, such as formal care teams and designated care or case managers, but there was considerable evidence of use of informal team-based care and care coordination nonetheless. It appears that many of these practices achieved the spirit, if not the letter, of the law in terms of key dimensions of PCMH.

CONCLUSIONS Small practices can achieve important aspects of the PCMH model of primary care, often with informal rather than formal mechanisms and strategies. The use of flexible, less formal strategies is important to keep in mind when considering implementation and assessment of PCMH-like initiatives in small practices.

Ann Fam Med 2013;11:S82-S89. doi:10.1370/afm.1491.

\section{INTRODUCTION}

$\mathrm{B}$ ecause nearly $90 \%$ of office-based patient visits occur in the small practice setting, it is important to investigate the unique challenges small practices face when they attempt to become medical homes. ${ }^{1}$ Prior research examining practice efforts to become recognized by the National Committee for Quality Assurance (NCQA) as a patient-centered medical home $(\mathrm{PCMH})$ have demonstrated that the extent of "medical homeness" in a practice is positively associated with the size of the practice. ${ }^{2}$ Small practices have smaller patient panels, which can make consistent performance measurement, and thereby the ability to assess change, more challenging. ${ }^{2,3}$ In addition, these practices also tend to have limited financial and human resources, which can make it more difficult for them to generate the documentation needed to meet NCQA criteria for recognition. ${ }^{4}$ As such, even when there is a will to do so, small practices may have difficulty implementing the broad practice change necessary to become a PCMH. ${ }^{5}$ The prevalent culture in small practices-physician centric, lacking in communication among physicians, authoritarian leader- 
ship, and underuse of midlevel clinicians_- can also be a major barrier to meaningful change. ${ }^{6}$ Research has shown the importance of preexisting structural capabilities and especially motivated leadership in the success of interventions geared toward practice change and improvement in delivery of preventive services. ${ }^{5,7-9}$

Exacerbating the problem of small practice transformation, common definitions of the elements of PCMH may underrepresent or exclude small practices. ${ }^{9}$ For example, the concept of care teams, in which a team of individuals at the practice level, including nonphysicians, work together to manage patients' care, is a core component associated with the $\mathrm{PCMH}$ model ${ }_{1}^{10,11}$ but in a solo practice, this concept is largely inapplicable if there are no other staff or physicians present. ${ }^{12}$ Other dimensions of the typical PCMH model are not readily feasible in small, resource-constrained practices either, such as the hiring of a dedicated care or case manager. ${ }^{13}$ Despite these challenges, it is possible that small practices are achieving the goals of case management in creative ways. ${ }^{14}$

In this multimethod study, researchers from New York University and the Primary Care Information Project (PCIP), a bureau of the New York City Department of Health and Mental Hygiene, collaborated to describe the experiences of small urban practices serving racially diverse and predominantly low income communities. All practices in this study participated in PCIP. We used data from a survey of clinicians in these practices to describe the practices in terms of practice and patient characteristics, relevant experiences before PCIP, and self-reported aspects of the PCMH model present in their practices. This study is the first product of an ongoing research project whose main goals are to illuminate the extent to which small urban practices realize the dimensions of the PCMH model, factors predicting adoption of this model, and the degree to which predictors and dimensions of PCMH relate to quality of care and patient outcomes.

\section{The Program}

PCIP was established in 2005 before the existence of Regional Extension Centers to assist primary care practices in New York City serving patients in disadvantaged neighborhoods to implement and use electronic health records (EHRs). ${ }^{15}$ The mission of PCIP is to improve population health and improve the delivery of clinical preventive services, and EHR implementation is one component of a multipronged strategy for achieving these goals. ${ }^{16}$ PCIP subsidized EHR software licenses, training, and implementation services for practices serving at least $10 \%$ Medicaid or uninsured patients. Practices were responsible for paying a technical assistance fee $(\$ 4,000$ per full-time equivalent of a clinician), purchasing their own hardware, hiring an information technology consultant for ongoing information technology support, and paying for Internet use and billing and electronic prescribing interfaces. Some practices serving extremely low income neighborhoods were eligible for additional subsidies or grants that provided costs of hardware, technical assistance fees, and rebates. ${ }^{9}$ All practices received training and consultation on quality improvement processes as part of the technical assistance provided by PCIP. In addition, practices could apply for NCQA PCMH recognition through PCIP's multisite application that streamlined some of the required documentation and provided staff support to help practices document or implement policies and processes to meet PCMH standards.

\section{METHODS}

\section{Sample}

Primary care practices involved with PCIP were eligible for inclusion in the overall project sample if they had 5 or fewer clinicians; were serving a predominantly adult population; had used the eClinicalWorks EHR system provided through PCIP for at least 1 year as of October 2009; and received at least 2 quality improvement (QI) visits from PCIP staff before October 2009 (or, for a small number of practices, were determined by PCIP staff to have advanced processes or capabilities in place that obviated the need for QI visits). These eligibility criteria were selected partly in response to requirements of the Agency for Healthcare Research and Quality Request for Application funding the project, but also because these practices were judged to be most likely to be moving toward implementation of aspects of the PCMH model, in that they had the working capacity to monitor and track patients with the EHR, had been trained by a QI specialist on workflow design, had established practice processes and policies for care management, had been aware of or were already using quality measurement, and had been able to conduct continuous clinical QI activities. Nevertheless, we anticipated that we would discover considerable variability in the various dimensions of $\mathrm{PCMH}$ among the 148 practices that met this definition. This report focuses on the 94 practices among these 148 whose sole primary care clinician or a clinician completed a questionnaire designed to assess key aspects of PCMH.

\section{Data Sources}

Data used for the reported analyses came from 2 sources: PCIP administrative data and a practice assessment survey administered in summer 2012. Administrative data were derived from PCIP's in-house Salesforce database, which is a commercially available, Web- 
based customer relationship management application that PCIP uses to monitor activities with the practices (eg, site visits with QI or other PCIP staff, attendance at classes or seminars hosted by PCIP or the vendor), maintain program administration and contact information, and track practice milestones such as initial contact for recruitment and the date of full ("go-live") implementation of the EHR.

We developed a questionnaire specifically for use in this study. To assess dimensions or components of PCMH model implementation, the questionnaire used constructs drawn from multiple surveys investigating primary care, the medical home, and chronic disease models. ${ }^{12,17-21}$ In developing the questionnaire, we were guided by the conceptual framework of PCMH proposed by Rittenhouse et al. ${ }^{2}$ In our survey, we measured 6 of the 7 features of PCMH they described: (1) each patient has a personal physician, (2) use of whole-person orientation, (3) use of team-based care, (4) coordination and integration of care across the health system, (5) a focus on quality and safety; and (6) timely access to care and communication. ${ }^{2}$ (The 7 th principle, payment reform, was beyond the scope of a practice assessment survey.) Although we drew from existing surveys, in many cases we modified questions and constructs to better reflect the realities and constraints faced by small practices with limited resources, and to allow practices to report a broader range of mechanisms or strategies used to implement components of PCMH. The questionnaire also collected data on practice characteristics and experiences before participation in PCIP (a copy of the full questionnaire is available from the corresponding author).

We sent the questionnaire to the clinician (medical doctor, doctor of osteopathy, nurse practitioner, or physician assistant) identified by PCIP as the sole or lead clinician in the practice for completion; other clinicians in the practice were eligible to complete the questionnaire if the lead clinician was unavailable. After pilot testing among comparable clinicians and making minor revisions on the basis of their feedback, we administered the questionnaire primarily online (with a paper option available); the questionnaire took 20 to 40 minutes to complete. The vast majority of the questionnaires were completed by the PCIP-identified clinician. Respondents received a $\$ 100$ gift card in appreciation for their time.

\section{RESULTS}

\section{Comparability of Survey Respondents to Overall Sample}

To assess comparability of the 94 respondents to the larger sample of 148 practices we approached to participate in the survey, we used data available through
Salesforce. Respondents were very similar to the 148 -practice sampling frame on proportion that are solo practices, percentage of patient panel insured by Medicaid, and PCMH recognition from NCQA. They also did not differ from the larger group in terms of the number of QI visits they had received from PCIP and the length of time they had been using their EHR systems. We are thus reasonably confident that survey respondents were an unbiased subset of all practices approached to be surveyed, and did not represent a more or less advantaged subgroup of practices, or were more or less motivated in terms of working with PCIP and implementing their EHR system.

\section{Practice Characteristics}

Respondents reported an average of fewer than 2 clinicians in the practice, including part-time clinicians, and two-thirds of responding practices were solo practices (Table 1). The practices in this sample served a diverse and disadvantaged patient population. On average, two-thirds of patients were nonwhite, almost one-half were covered by Medicaid, and one-third were more comfortable speaking a language other than English. Most practices were unaffiliated before joining PCIP, and none were Federally Qualified Health Centers (data not shown). The questionnaire did not directly query respondents on the financial status of their practices, but the great majority reported worrying about meeting monthly expenses, and a substantial minority indicated that they were unable to acquire equipment and staff as needed.

\section{Experiences Before Participation in PCIP}

Before joining PCIP, most practices had computers of some variety, but only $21 \%$ had an EHR (Table 2). The majority of respondents indicated that their practices had not been using management systems, patient registries, or electronic prescription before PCIP, and threequarters reported that they had not implemented any formal QI efforts before PCIP.

\section{Dimensions of the PCMH Model}

The majority of these small practices reported having implemented most dimensions of PCMH addressed by the survey (Table 3). Nonsolo practices reported that most patients saw the same clinician each visit and that more than one-half of all practices reported that all patients could identify their primary care clinician by name (dimension 1). Respondents also reported having timely access and communication and off-hour coverage (dimension 6). The practices demonstrated greater variability in other PCMH dimensions, but overall, respondents reported having processes or presence of many key aspects of PCMH. 


\section{Table 1. Practice Characteristics $(\mathrm{N}=94)$}

\begin{tabular}{|c|c|}
\hline Characteristic & Value \\
\hline Clinicians (full and part time), mean (SD), No. & $1.96(1.75)$ \\
\hline Solo clinicians, \% & 67 \\
\hline Other staff (full and part time), mean (SD), No. & $4.77(3.67)$ \\
\hline Annual patient visits, mean (SD), No. & $6,791(6,106)$ \\
\hline Patients, mean (SD), No. & $2,413(2,683)$ \\
\hline Patients best served in another language, \% (SD) & $32(31)$ \\
\hline Uninsured patients, \% (SD) & $11(20)$ \\
\hline Patients with Medicaid coverage, \% (SD) & $42(29)$ \\
\hline Nonwhite patients, \% (SD) & $66(32)$ \\
\hline \multicolumn{2}{|l|}{ Affiliations before joining PCIP, \%b } \\
\hline $\begin{array}{l}\text { Network(s) of outpatient practices that share } \\
\text { resources for managing patient care }\end{array}$ & 5 \\
\hline Independent Practice Association(s) & 30 \\
\hline $\begin{array}{l}\text { Hospital(s) over and above admitting/attend- } \\
\text { ing privileges }\end{array}$ & 11 \\
\hline Financially and/or contractually linked network(s) & 1 \\
\hline Academic medical center(s) & 4 \\
\hline Faith-based institution(s) & 1 \\
\hline Community-based institution(s) & 1 \\
\hline Other entity/entities or system(s) & 1 \\
\hline No prior affiliation(s) & 51 \\
\hline \multicolumn{2}{|l|}{ Self-reported financial viability, \% } \\
\hline \multicolumn{2}{|l|}{ Able to acquire equipment and staff as needed: } \\
\hline Strongly disagree & 10 \\
\hline Disagree & 26 \\
\hline Agree & 47 \\
\hline Strongly agree & 17 \\
\hline \multicolumn{2}{|l|}{ Worry about meeting monthly expenses: } \\
\hline Strongly disagree & 8 \\
\hline Disagree & 22 \\
\hline Agree & 42 \\
\hline Strongly agree & 29 \\
\hline \multicolumn{2}{|l|}{ PCIP = Primary Care Information Project. } \\
\hline \multicolumn{2}{|c|}{$\begin{array}{l}\text { ancluded medical doctor, doctor of osteopathy, nurse practitioner, or physi- } \\
\text { cian assistant. } \\
\text { b Practices were asked to check all that apply; thus, values total to more than } \\
100 \% \text {. }\end{array}$} \\
\hline
\end{tabular}

Small practices were relatively unlikely to report using some of the more formal mechanisms often associated with $\mathrm{PCMH}$. For example, very few had formal care teams (18 practices) or designated care or case managers (7), used Plan, Do, Study, Act (PDSA) techniques (9), or had a "great deal" of formal training in cultural competence (18), however, the practices demonstrated considerable use of less formal techniques to provide similar PCMH functions. More than one-half reported having informal care teams (57) and having monthly or more frequent meetings to review and plan care for patients (53). The great majority of practices reported having a structured process for reminding patients of upcoming appointments (87), for following up on missed appointments (81), and for systematically monitoring patients with chronic conditions (82).
Table 2. Practices' Previous Experience With Aspects of the Patient-Centered Medical Home ( $N=94)$

\begin{tabular}{lc}
\hline Experience & Practices, \% \\
\hline Had computers & 88 \\
Had an electronic health record in place & 21 \\
Used a management system & 37 \\
Used a patient registry & 17 \\
Electronically transmitted prescriptions & 18 \\
Had implemented quality improvement & 26 \\
activity/activities & \\
\hline
\end{tabular}

Respondents also reported high levels of coordination related to referrals and hospitalizations. Most practices had worked out strategies to communicate with their non-English-speaking patients. More than one-half of the practices each had implemented QI efforts to improve patient satisfaction (57) and had used data to assess the impact of QI efforts (55).

In terms of formal recognition, only one-third reported that they had not yet applied for NCQA $\mathrm{PCMH}$ recognition, and the rest had either achieved recognition or had an application pending. The majority of practices with PCMH recognition had Level 1 recognition.

Several areas for improvement for these practices were identified in the survey. Specifically, in terms of whole-person orientation, less than one-half of the practices reported usually or always discussing with patients alternative treatments (40 practices) and family planning or birth control (40). There was little evidence that these practices were consistently using their staff at the top of their skill set, as few practices reported using staff other than primary care clinicians (eg, registered nurses, medical assistants) for patient education (26) or for taking patient histories (28), and fewer than 10 used these staff to perform chronic disease screening. These practices also had limited connection to community programs and resources outside of the practice. For example, less than one-half of practices routinely (usually or always) referred patients for smoking cessation programs (42), and only slightly more than one-third referred to patient support groups (39). Finally, a minority of practices used formal performance measurement systems for individual clinicians (29) or the whole practice (34).

\section{DISCUSSION}

We found substantial implementation of key aspects of the PCMH among small New York City practices serving disadvantaged patient populations, despite considerable potential challenges to achieving PCMH 
Table 3. Selected Patient-Centered Medical Home Characteristics of Practices ( $\mathrm{N}=94$ )

\begin{tabular}{|c|c|c|c|}
\hline PCMH Characteristic & $\begin{array}{l}\text { Percent or } \\
\text { Mean (SD) }\end{array}$ & PCMH Characteristic & $\begin{array}{l}\text { Percent or } \\
\text { Mean (SD) }\end{array}$ \\
\hline \multirow{2}{*}{$\begin{array}{l}\text { Dimension 1: Each patient has a personal } \\
\text { physician }\end{array}$} & & \multicolumn{2}{|l|}{ Dimension 3: Team-based care } \\
\hline & & Formal care teams in place & 18 \\
\hline Patients usually/always see the same cliniciana & 90 & Informal care teams in place & 57 \\
\hline $\begin{array}{l}\text { All patients in the practice can identify their primary } \\
\text { care clinician or care team by name }\end{array}$ & 57 & $\begin{array}{l}\text { Nonclinician staff educate patients about prevention, } \\
\text { chronic illness, and/or depression }\end{array}$ & 43 \\
\hline \multicolumn{2}{|l|}{ Dimension 2: Whole-person orientation } & \multirow{2}{*}{\multicolumn{2}{|c|}{$\begin{array}{l}\text { Practice staff meet to review and plan care for } \\
\text { individual patients }\end{array}$}} \\
\hline \multirow{2}{*}{\multicolumn{2}{|c|}{$\begin{array}{l}\text { Clinician includes an adult patient's family in discus- } \\
\text { sion of his/her health }\end{array}$}} & & \\
\hline & & Daily & 10 \\
\hline Never/rarely & 7 & At least weekly & 10 \\
\hline Sometimes & 49 & At least monthly & 33 \\
\hline Usually & 34 & Less than monthly & 47 \\
\hline Always & 10 & \multicolumn{2}{|l|}{ Practice holds all-staff meetings } \\
\hline \multicolumn{2}{|l|}{$\begin{array}{l}\text { Clinician discusses diet and exercise guidelines with } \\
\text { patients }\end{array}$} & Never & 15 \\
\hline Never/rarely & 0 & Once a year & 12 \\
\hline Sometimes & 2 & Once a quarter & 29 \\
\hline Usually & 37 & Monthly & 34 \\
\hline Always & 61 & Weekly & 10 \\
\hline \multicolumn{2}{|l|}{ Clinician discusses depression with patients } & Practice staff have "huddle" meetings in which & 45 \\
\hline Never/rarely & 0 & $\begin{array}{l}\text { operational strategies and/or division of labor } \\
\text { is determined }\end{array}$ & \\
\hline Sometimes & 19 & Nonclinician staff provide patient education & \\
\hline Usually & 53 & Never/rarely & 28 \\
\hline Always & 28 & Sometimes & 42 \\
\hline \multicolumn{2}{|l|}{ Clinician discusses stress and anxiety with patients } & Usually & 16 \\
\hline Never/rarely & 0 & Always & 10 \\
\hline Sometimes & 20 & Nonclinician staff take patient history & \\
\hline Usually & 54 & Never/rarely & 45 \\
\hline Always & 26 & Sometimes & 23 \\
\hline \multicolumn{2}{|l|}{ Clinician discusses alternative treatments with patients } & Usually & 12 \\
\hline Never/rarely & 17 & Always & 16 \\
\hline Sometimes & 43 & Nonclinician staff perform chronic disease screening & \\
\hline Usually & 20 & Never/rarely & 70 \\
\hline Always & 20 & Sometimes & 16 \\
\hline \multirow{2}{*}{\multicolumn{2}{|c|}{$\begin{array}{l}\text { Clinician discusses family planning or birth control } \\
\text { services with patients }\end{array}$}} & Usually & 7 \\
\hline & & Always & 2 \\
\hline Never/rarely & 18 & \multirow{2}{*}{\multicolumn{2}{|c|}{$\begin{array}{l}\text { Clinicians speak to primary care clinicians outside } \\
\text { of their practices about cases }\end{array}$}} \\
\hline Sometimes & 42 & & \\
\hline Usually & 21 & Never/rarely & 21 \\
\hline Always & 19 & Sometimes & 49 \\
\hline \multirow{2}{*}{\multicolumn{2}{|c|}{$\begin{array}{l}\text { Resources used for translation with patients who } \\
\text { cannot communicate well in English }\end{array}$}} & Usually & 19 \\
\hline & & Always & 11 \\
\hline Family member & 63 & \multirow{2}{*}{\multicolumn{2}{|c|}{$\begin{array}{l}\text { Dimension 4: Care coordinated and integrated } \\
\text { across health care system }\end{array}$}} \\
\hline On-site bilingual clinical staff & 62 & & \\
\hline On-site bilingual nonclinical staff & 17 & Designated care or case manager & 7 \\
\hline Telephone-based translation service & 6 & Nondesignated staff functioning as care or case & 55 \\
\hline \multicolumn{2}{|l|}{$\begin{array}{l}\text { Languages in which patient education materials are } \\
\text { made available }\end{array}$} & $\begin{array}{l}\text { manager } \\
\text { Use electronic prescribing }\end{array}$ & 94 \\
\hline English & 96 & \multicolumn{2}{|l|}{ Have structured processes in place for: } \\
\hline Spanish & 68 & Reminding patients of upcoming appointments & 87 \\
\hline Other & 20 & Following up with patients who have missed & 81 \\
\hline \multicolumn{2}{|l|}{$\begin{array}{l}\text { Amount of formal training that practice staff have } \\
\text { used to improve their skills in patient communica- } \\
\text { tion or cultural competence }\end{array}$} & $\begin{array}{l}\text { appointments } \\
\text { Contacting patients who have not been seen } \\
\text { in } \geq 1 \text { year }\end{array}$ & 59 \\
\hline Little or none & 47 & \multirow{3}{*}{$\begin{array}{l}\text { Systematically monitoring patients with chronic } \\
\text { conditions }\end{array}$} & 82 \\
\hline Some & 29 & & \\
\hline Great deal & 18 & & continued \\
\hline
\end{tabular}


Table 3. Selected Patient-Centered Medical Home Characteristics of Practices ( $N=94)$ (continued)

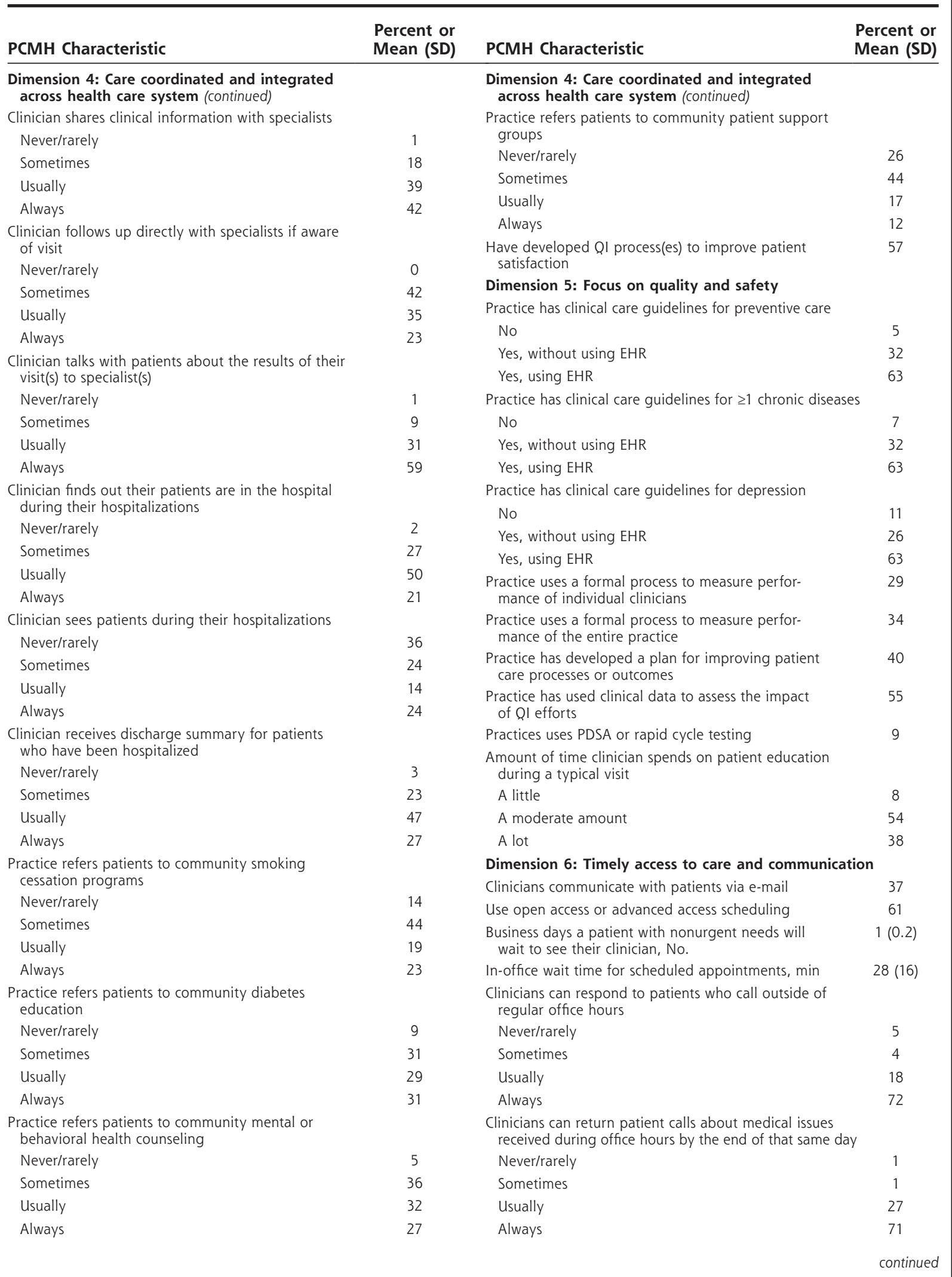

EHR = electronic health record; HIT = health information technology; PCMH = patient-centered medical home; PDSA = Plan, Do, Study, Act; QI = quality improvement. Note: Clinicians refers to medical doctors, doctors of osteopathy, nurse practitioners, or physician assistants. 


\begin{tabular}{|c|c|c|c|}
\hline PCMH Characteristic & $\begin{array}{l}\text { Percent or } \\
\text { Mean (SD) }\end{array}$ & PCMH Characteristic & $\begin{array}{l}\text { Percent or } \\
\text { Mean (SD) }\end{array}$ \\
\hline \multirow{2}{*}{$\begin{array}{l}\text { Dimension 6: Timely access to care and } \\
\text { communication (continued) }\end{array}$} & & \multicolumn{2}{|l|}{ PCMH recognition and related incentives } \\
\hline & & Have not applied for $\mathrm{PCMH}$ recognition & 32 \\
\hline \multirow{3}{*}{$\begin{array}{l}\text { Practice arrangements for patients to see a doctor } \\
\text { or nurse for nonemergent problems on evenings } \\
\text { and/or weekends without going to the emergency } \\
\text { department }\end{array}$} & & Application pending & 19 \\
\hline & & Receiving medical home/PCMH incentives & 38 \\
\hline & & Receiving HIT/meaningful use incentives & 59 \\
\hline Practice is open some evenings and/or weekends & 68 & \multirow{5}{*}{$\begin{array}{l}\text { Receiving } Q 1 / \text { performance incentives from } \\
\text { health plan }\end{array}$} & \multirow[t]{5}{*}{27} \\
\hline Have made arrangements with other practices & 4 & & \\
\hline $\begin{array}{l}\text { Have made arrangements with } \geq 1 \text { urgent care } \\
\text { center(s) }\end{array}$ & 5 & & \\
\hline Other & 17 & & \\
\hline No specific arrangements & 14 & & \\
\hline
\end{tabular}

EHR = electronic health record; HIT = health information technology; PCMH = patient-centered medical home; PDSA = Plan, Do, Study, Act; QI = quality improvement. Note: Clinicians refers to medical doctors, doctors of osteopathy, nurse practitioners, or physician assistants.

a Question asked only of respondents who identified themselves as not solo practitioners as it was assumed that in a solo practice patients would necessarily seem the same physician every time.

implementation. These practices were involved in an initiative to enhance primary care, primarily through implementation of a comprehensive EHR system and technical assistance from QI specialists. The majority of these practices served large numbers of low-income patients belonging to racial minorities, often with limited proficiency in English; on average, 42 of our practices' patient panels were covered by Medicaid, far higher than the average of about 15 for solo practices and small practices nationwide. ${ }^{22}$ These small practices were largely not affiliated with academic medical centers, medical groups, or independent practice associations, and most respondents worried about finances. Before joining PCIP, most of the practices owned computers but had limited experience with EHR systems, electronic prescribing, use of patient registries, or QI efforts. Nevertheless, the majority has applied for formal PCMH recognition, and close to one-half had achieved at least Level 1 recognition from NCQA.

We were especially struck by the relatively low use of formal mechanisms such as formal care teams and designated care or case managers, but there was considerable evidence of use of informal team-based care and care coordination nonetheless. It appears that many of these practices achieved the spirit, if not the letter, of the law in terms of key dimensions of PCMH. This use of more flexible, less formal strategies is important to keep in mind when considering implementation of PCMH-like initiatives with small practices and when assessing the effectiveness of such initiatives.

Most but not all of the practices in this sample had applied for PCMH recognition from NCQA. These resource-strapped practices could undoubtedly have benefitted from the financial incentives available to practices with NCQA recognition through New
York State Medicaid, yet not all could or did avail themselves of this opportunity, even with substantial assistance or encouragement from PCIP. Anecdotal reports from these practices suggested that many simply did not have the time or capacity to provide the documentation necessary for formal PCMH recognition, or that formal recognition was not important to them, despite available financial incentives. Streamlining or otherwise minimizing the process associated with application for recognition could be an important strategy to assist practices like these in accessing incentives, which in turn could enable them to provide enhanced primary care.

A variety of contextual factors are relevant to understanding our study's findings and transporting the findings to other settings. These factors and their implications are discussed in the Supplemental Appendix (available online at http://annfammed.org/ content/11/Suppl_1/S82/suppl/DC1).

This study has some limitations. The sample of practices, although representative of small practices involved with PCIP, may differ in important ways from practices not associated with PCIP. We cannot infer that similar practices without such assistance do or could incorporate PCMH elements to the degree these practices have with assistance. As this study was not an evaluation of PCIP, we also cannot infer that participation in PCIP was the causal agent in terms of achieving PCMH dimensions. Furthermore, the primary data are self-reported and may overestimate or underestimate actual practice and behaviors because of recall error or reporting bias.

Despite these limitations, this study demonstrates the capacity of small practices to embrace multiple aspects of the PCMH model, at least with the assis- 
tance of an external entity such as PCIP. Survey results indicate that small practices can be resourceful and creative in overcoming challenges or redefining processes to enact PCMH-like functions. Future research should further investigate the nature and use of alternate strategies to achieve the components of PCMH in resourcestrapped environments. Research linking PCMH to measures of quality of care and patient outcomes is also critical to a more thorough understanding of the value of assisting small practices serving disadvantaged patient populations to implement patient-centered changes in the delivery of primary care.

To read or post commentaries in response to this article, see it online at http://www.annfammed.org/content/11/Suppl_1/S82.

Key words: patient-centered medical home; primary care; vulnerable populations; change, organizational; practice-based research

Submitted July 31, 2012; submitted, revised, December 4, 2012; accepted December 27, 2012.

Funding support: This study was funded by the Agency for Healthcare Research and Quality.

Disclaimer: The content is solely the responsibility of the authors and does not necessarily represent the official views of the Agency for Healthcare Research and Quality.

Acknowledgments: The authors would like to acknowledge the contributions of Jason J. Wang, PhD, senior director, Program Evaluation and Analysis; Jisung Cha, PhD, SAS analyst; and Elizabeth Wolff, MD, MPA, executive director, Quality Improvement and Health Outcomes of the Primary Care Information Project, New York City Department of Health and Mental Hygiene.

\section{References}

1. Hing E, Burt CW. Office-based medical practices: methods and estimates from the National Ambulatory Medical Care Survey. Adv Data. 2007;(383):1-15.

2. Rittenhouse DR, Casalino LP, Shortell SM, et al. Small and mediumsize physician practices use few patient-centered medical home processes. Health Aff (Millwood). 2011;30(8):1575-1584.

3. Friedberg MW, Safran DG, Coltin KL, Dresser M, Schneider EC. Readiness for the patient-centered medical home: structural capabilities of Massachusetts primary care practices. J Gen Intern Med. 2009;24(2):162-169.

4. Landon BE, Normand SL. Performance measurement in the small office practice: challenges and potential solutions. Ann Intern Med. 2008;148(5):353-357.

5. Wolfson D, Bernabeo E, Leas B, Sofaer S, Pawlson G, Pillittere D. Quality improvement in small office settings: an examination of successful practices. BMC Fam Pract. 2009;10:14.
6. Nutting PA, Crabtree BF, McDaniel RR. Small primary care practices face four hurdles-including a physician-centric mind-set-in becoming medical homes. Health Aff (Millwood). 2012;31(11):2417-2422.

7. Homer CJ, Baron RJ. How to scale up primary care transformation: what we know and what we need to know? J Gen Intern Med. 2010;25(6):625-629.

8. Nutting PA, Miller WL, Crabtree BF, Jaén CR, Stewart EE, Stange KC. Initial lessons from the first national demonstration project on practice transformation to a patient-centered medical home. Ann Fam Med. 2009;7(3):254-260.

9. Samantaray R, Njoku VO, Brunner JW, Raghavan V, Kendall ML, Shih SC. Promoting electronic health record adoption among small independent primary care practices. Am J Manag Care. 2011;17(5): 353-358.

10. Rittenhouse DR, Shortell SM. The patient-centered medical home: will it stand the test of health reform? JAMA. 2009;301(19):2038-2040.

11. American Academy of Family Physicians, American Academy of Pediatrics, American College of Physicians, American Osteopathic Association. Joint Principles of the Patient-Centered Medical Home. 2007. http://medicalhomeinfo.org/downloads/pdfs/jointstatement. pdf. Accessed Nov 28, 2012.

12. The Commonwealth Fund. 2012 Commonwealth Fund International Survey of Primary Care Doctors. 2009. http://www.commonwealth fund.org/Surveys/2012/Nov/2012-International-Survey.aspx. Accessed Nov 28, 2012.

13. Goldberg DG, Mick SS. Medical home infrastructure: effect of the environment and practice characteristics on adoption in Virginia. Med Care Res Rev. 2010;67(4):431-449.

14. Moore LG, Wasson JH. The ideal medical practice model: improving efficiency, quality and the doctor-patient relationship. Fam Pract Manag. 2007;14(8):20-24.

15. Mostashari F, Tripathi M, Kendall M. A tale of two large community electronic health record extension projects. Health Aff (Millwood). 2009;28(2):345-356.

16. Frieden TR, Mostashari F. Health care as if health mattered. JAMA. 2008;299(8):950-952.

17. Center for Health Care Strategies Inc (CHCS). Advancing Primary Care: Opportunities to Support Care Delivery Redesign in Practices Serving Medicaid and Racially and Ethnically Diverse Patients. 2012. http:// www.chcs.org/usr_doc/advancingprimarycare080912.pdf.Accessed Nov 28, 2012.

18. Shortell SM. National Survey of Physician Organizations and the Man agement of Chronic Illness II (Medical Groups). Berkeley, CA: University of California; 2008.

19. Kralewski J, Dowd BE, Kaissi A, Curoe A, Rockwood T. Measuring the culture of medical group practices. Health Care Manage Rev. 2005;30(3):184-193.

20. The National Committee for Quality Assurance (NCQA). Practice Systems Assessment Survey: Primary Care Version (PSAS-PC). Washington, DC: NCQA; 2004.

21. The National Committee for Quality Assurance (NCQA). Physician Practice Connections - Patient Centered Medical Home (PPC - PCMH) Version Standards. Washington, DC: NCQA; 2007.

22. Boukus E, Cassil A, O'Malley AS. A snapshot of U.S. physicians: key findings from the 2008 Health Tracking Physician Survey. Data Bull (Cent Stud Health Syst Change). 2009;(35):1-11. 